\title{
KEBAIKAN DAN KEBURUKAN MENURUT ZOROASTRIANISME (MENGENAL AJARAN MORAL ZARATHUSTRA)
}

\author{
Ahmad Kholil \\ Fakultas Humaniora dan Budaya UIN Maulana Malik Ibrahim Malang. \\ Jalan Gajayana 50 Malang. Telp. 081807765237 \\ email: Khumi2005@yahoo.com
}

\begin{abstract}
There are always two values in religions which are on the opposite sides of each other, i.e. the goodness and the badness. Al Quran describes these two qualities with various uslub related to Arabic culture: al hasanat and al sayyi'at. The goodness and the badness are always "in a war" until the end of the world. As religions, both Islam and Zoroaster rely on the faith toward God to edify their followers in performing the goodness and leaving the badness. This paper reviews to some extent-some commonalities between the moral teachings of Islam and those of Zoroaster (excluding few shared concepts of theology and creation process of the first living man). Moslems are required to apply the concept of amar ma'ruf nahi munkar, while Zoroastrians are called to implement the four principles of moral attitude putting the weapon down, ending any quarrel, exploring the independence, and performing good attitude.
\end{abstract}

Selalu terdapat dua nilai di dalam setiap agama yang letaknya saling bertolak belakang satu sama lain, yaitu kebaikan dan keburukan. Al Quran menggambarkan dua kualitas ini dengan berbagai uslub terkait dengan budaya Arab: al hasanat dan al sayyi'at. Kebaikan dan keburukan selalu "berperang" hingga akhir dunia. Sebagai agama, baik Islam maupun Zoroaster menyandarkan kepercayaan mengenai kebaikan dan keburukan ini kepada Tuhan untuk mendorong pengikutnya melakukan kebaikan dan menghindari keburukan. Tulisan ini memaparkan, pada batas tertentu, kesamaan antara ajaran moral di dalam Islam dan Zoroaster (di luar beberapa konsep yang sama tentang ketuhanan dan proses penciptaan manusia pertama). Kaum muslim dituntun 
untuk mengaplikasikan konsep amar ma'ruf nahi munkar, sedangkan para penganut Zoroaster dituntun untuk mengimplementasikan empat prinsip moral dan perilaku, yaitu menurunkan senjata, mengakhiri berbagai pertengkaran, mengeksplorasi kemerdekaan, dan menunjukkan perilaku yang baik.

Key words: Islam, Zoroaster, theology, morality, culture

\section{Pendahuluan}

Secara theologis-filosofis, kebaikan, kesempurnaan, keindahan, kesucian, kekuatan, kemandirian dan segala kualifikasi nilai yang menunjuk kepada hal yang serupa merupakan kualitas ontologis (امر وجودى). Sedangkan kualifikasi yang sebaliknya, seperti keburukan, kekurangan, kecacatan, kejelekan, kekotoran, kelemahan, dan ketergantungan kepada yang lain adalah kualitas-kualitas yang relatif dan tiada secara objektif. Dengan kata lain, yang pertama itu mewujud dalam eksistensi yang utuh dan mandiri, sedangkan yang kedua tidak utuh dan terikat dengan eksistensi yang lain. Sesuatu dikatakan baik karena padanya telah terpenuhi beberapa kualifikasi yang dibutuhkan untuk disebut baik. Sedangkan dikatakan jelek karena ada kualifikasi yang tidak terpenuhi padanya untuk disebutnya sebagai baik.

Dalam tradisi kefilsafatan, pembahasan tentang apa yang baik dan apa yang buruk ini lazim dipahami dengan istilah etika. Dalam tradisi tersebut, etika dianggap sebagai usaha manusia dengan akal budinya untuk mendapatkan teori tentang penyelenggaraan hidup yang baik. Persoalan ini mucul ketika moralitas seseorang atau suatu masyarakat mulai dirasa perlu untuk ditinjau kembali secara kritis. Paul W. Taylor, seperti dikutip Komaruddin Hidayat dalam artikel Yayasan Paramadina yang membahas ajaran al Quran dan relevansinya dalam kehidupan modern, mengatakan bahwa moralitas itu berkenaan dengan tingkah laku manusia yang konkrit praktis, sedangkan etika beroperasi pada level teoritis. Adapun nilai-nilai etis yang dipahami, diyakini, dan berusaha diwujudkan dalam kehidupan nyata di tengah masyarakat seringkali disebut ethos. Etika dalam pengertian yang umum biasa juga disebut dengan akhlaq.

Etika sebagai cabang filsafat, memandang tindakan manusia ini dapat dibedakan menjadi dua macam, yaitu tindakan objektivisme dan tindakan subjektivisme. Yang pertama berpandangan bahwa nilai kebaikan suatu tindakan bersifat objektif, terletak pada substansi tindakan itu sendiri. Paham ini melahirkan apa yang disebut dengan madzhab rasionalisme dalam etika. Menurut kelompok ini, suatu tindakan disebut baik bukan karena si pelaku senang melakukannya, atau tindakan tersebut sejalan dengan kehendak 
masyarakat, melainkan semata karena keputusan rasionalisme universal yang mendorong untuk melakukan tindakan tersebut. Tokoh utama pendukung aliran ini ialah Immanuel Kant, sedangkan dalam Islam, pada batas tertentu, ialah kaum Mu'tazilah, yang dikenal sebagai kelompok rasionalis awal dalam Islam. Madzhab kedua adalah subjektivisme. Menurut madzhab ini suatu tindakan disebut baik apabila sejalan dengan kehendak atau pertimbangan subjek tertentu. Subjek tersebut bisa saja berupa subjektivisme kolektif seperti kelompok tertentu atau masyarakat atau juga Tuhan. Dalam Islam, paham demikian direpresentasikan oleh golongan Asy'ariyah. Menurut paham Asy'ariyah, nilai kebaikan suatu tindakan bukannya terletak pada objektivitas nilainya, melainkan pada ketaatannya pada kehendak Tuhan (Makdisi, 2005: 50). Bila telah diketahui suatu tindakan itu baik, manusia berkewajiban secara moral untuk melakukannya (Misbah, 2006: 51).

Terlepas dari beberapa perbedaan mengenai pandangan terhadap nilai sebuah perbuatan, apa yang hendak ditulis pada makalah ini adalah sebuah perspektif yang berusaha menyoroti doktrin keagamaan yang berhubungan dengan amal perbuatan manusia, tentang moralitas. Islam sebagai agama akhlak sangat mengedepankan moral sosial religius dalam segala tindakan umatnya dalam wujud memerintah kepada yang baik dan mencegah dari yang munkar (QS Ali Imron: 104). Ibadah sebagai wujud pengabdian manusia kepada Tuhannya, dalam pandangan Islam, bukan hanya dalam wujud ritual saja, namun menyangkut seluruh aktivitas, termasuk aktivitas yang nampak duniawi sekalipun. Keyakinan bahwa semua aktivitas itu adalah ibadah meniscayakan kehadiran Tuhan di manapun sang hamba berada. Dengan demikian, ia tidak punya ruang kosong untuk berlaku kafir atau berkhianat atas "kepercayaan" yang telah diberikan Tuhan kepadanya. Dengan ungkapan lain, sang hamba dituntut untuk selalu berbuat baik. Senada dengan ini, para penganut Zoroaster, dengan keyakinannya akan eksistensi Tuhan harus rela berbaiat dengan suara lantang agar menjunjung pikiran yang baik, perkataan yang baik, dan perbuatan yang baik (Assagaf, 2009: 140).

Dalam ensiklopedi Funk and Wagnalls disebutkan bahwa penganut Zoroaster di dunia saat ini ada sekitar 140.000 orang, dengan sebaran di Iran, India, Timur Tengah dan Timur Dekat (Assagaf, 2009: 163). Sementara Putu Putra dalam artikel "Zoroaster" menyebut sekitar 125.000 orang. Sebelum jauh menelisik ke keyakinan tempo dulu Persia dalam sorot pandang etika, ada baiknya dikenalkan lebih dulu situasi aktual Iran yang dulu menjadi basis munculnya agama Zoroaster, di samping keberadaannya yang menjadi basis 
kajian Filsafat Islam dari dulu hingga saat ini.

\section{Persia Dari Klasik Hingga Modern}

Persia wilayah yang didiami Bangsa Iran memiliki sejarah peradaban yang sangat gemilang sejak ribuan tahun sebelum Masehi. Wilayah yang terdiri dari gunung-gunung bersalju, lembah hijau dan padang pasir yang tandus ini telah dihuni manusia lebih dari 100 ribu tahun yang silam (Smith, 2009: 4-9). Iran klasik, yang dikenal dengan sebutan Persia adalah sebuah wilayah kerajaan besar yang meliputi Babylonia, Palestina, Suriah, seluruh Asia Kecil bahkan hingga ke Mesir. Kejayaan itu berlangsung hingga tahun 330 SM di mana kerajaan Romawi di bawah kendali Alexander Agung yang menaklukkan wilayah Persia, dan dari sinilah mulai terjadi proses Hellenisme, bertemunya semangat budaya Barat dan Timur. Pada masa-masa berikutnya, kawasan ini menjadi medan perebutan kekuasaan sejumlah suku penakluk (Assagaf, 2009: 21).

Bangsa Arab, dengan semangat Islamnya berhasil memasuki wilayah ini pada tahun $637 \mathrm{M}$, yaitu melalui perang Qadisiyyah, di mana imperium Persia takluk kepada kaum muslimin yang dipimpin oleh Amir al Mukminin, Khalifah Umar bin al Khattab. Pada tahun 641 M, setelah melalui peperangan Nehavand, seluruh imperium Persia yang waktu itu dipimpin oleh Raja Yazdajird jatuh ke tangan kaum muslimin. Sejak itulah, seluruh kawasan Persia yang semula menganut ajaran agama Zoroaster beralih ke agama Islam. Dinasti dan pemerintahan yang memimpin Persia silih berganti pasca-Khulafa' Rasyidun, mulai Dinasti Umawiyah (661-750 M), Abbasiyah (750-1258 M), dinasti-dinasti lokal yang mengelilingi pemerintahan Abbasiyah seperti: Tahirids (820-872 M) di Khurasan, Samanids (900-994 M) di Transoxiana-Khurasan, dan Saffarids (867-909 M) di Kirman-Khurasan (Ensiklopedi Islam, 1994: 242).

Mayoritas penduduk Persia bermadzhab Syi'ah, hal ini mungkin dikarenakan akumulasi sejarah yang sangat kompleks, sebagian di antaranya akibat kekecewaan politik orang-orang Persia terhadap Bangsa Arab, juga adanya pertemuan kultural antara Arab-Persia yang dilembagakan melalui pernikahan antara Hussain putra Ali bin Abi Thalib dengan putri Kaisar Persia. Andil yang sangat besar dalam persoalan madzhab ini adalah ketika dinasti Safawiyah berkuasa di mana secara resmi penerapan ortodoksi agama dilakukan dengan menganut sufisme dengan corak Syi'ahnya. Apa yang dilakukan Dinasti Safawi ini merupakan upaya politik untuk membedakan wilayah kekuasaannya dengan wilayah-wilayah Sunni di sekitarnya, Turki 
Utsmani dan Mughal di India (Ensiklopedi Islam, 1994: 189).

Pada tahun 1219 Jengis Khan dari Mongol menyerbu wilayah ini dan 37 tahun berikutnya kekuasaan diserahkan kepada cucunya Hulagu Khan yang dikenal dengan dinasti Ilkhanids. Keturunan Mongol berkuasa di wilayah ini hingga tahun $1335 \mathrm{M}$. Setelah masa kekuasaan Mongol itu, orang-orang Turki yang tergabung dalam kelompok Black Sheep Turkeman dan White Sheep Turkemen juga pernah menikmati kekuasaan di sini hingga 1500-an (Lapidus, 2000: 21). Sebelum mendapat campur tangan Eropa, terutama Inggris saat kekuasaan dipegang Dinasti Qajar mulai tahun 1779 sampai 1925 M, telah banyak kekuasaan yang turut andil membentuk karakter Bangsa Persia-Iran ini. Dalam pembentukan sebagai negara modern bisa dicatat beberapa dinasti dan kekuasaan yang mengatur kawasan ini, yakni Safawiyah (1507-1772 M), Afgans Mahmud-1722 M, Nadir Shah-1736-1747 M, Zands-1747- 1779 M, dan baru kemudian dinasti Qajar-1779-1925 M (Ensiklopedi Islam, 1994: 31-33).

Sejak 11 Februari 1979, melalui revolusi Islam yang dipimpin ulama terkemuka Ayatullah Khomeini, sistem kerajaan yang telah ratusan tahun berlaku di Iran dihapus dan diganti dengan sistem pemerintahan modern dengan sebutan Republik Islam Iran. Di samping ada pemerintahan dan parlemen yang menjalankan dan mengawasi pemerintahan, ada juga para faqih atau ulama karismatik yang ikut mengontrol perjalanan pemerintahan dan kehidupan sosial keagamaan penduduk. Lembaga ini disebut Wilayah al Faqih yang sejak awal berdirinya, tahun 1979 tersebut dipimpin Imam Khomeini. Sebagai pemimpin atau Wali Faqih, Imam Khomeini tidak duduk dalam jajaran eksekutif, melainkan hanya sebagai pembimbing dan pengontrol. Setelah Sang Imam wafat posisinya digantikan para ulama karismatik lainnya. Baru pada 4 Juni 1989, untuk menghindari konflik, kedudukan sebagai pemimpin itu digantikan oleh anak Imam Khomeini yaitu Ali Khomeini.

Dalam sistem pemerintahan Iran dikenal juga istilah eksekutif, legislatif, dan yudikatif. Kepala Pemerintahan dipegang oleh seorang presiden. Pemilu dilakukan 4 tahun sekali untuk memilih 290 anggota parlemen. Sejak tahun 2000, Iran memasuki babak baru dengan sistem multipartai. Sebelumnya, pemilu Iran hanya diikuti tiga kontestan, yaitu: Majma'e Rouhaniyoun Mobarez, Jame'e Rouhaniyrt Mobarez, dan Partai Pelaksana Pembangunan (Thohir, 2009: 192). Saat ini yang memegang tampuk pimpinan di lembaga eksekutif adalah Mahmoud Ahmadi Nejad. Ia telah memenangkan pemilu presiden untuk yang kedua pada 3 Agustus 2009.

Pada aspek sosial budaya, penduduk asli Iran adalah Arya-Iran yang 
berasal dari padang rumput Kaukasian dan diperkirakan telah mendiami kawasan ini sejak 1500 SM. Di samping orang-orang Arya ada juga beberapa suku yang lain sesuai dengan asal usul leluhurnya. Etnik terbesar saat ini memang Arya seperti Medes dan Parsa (orang-orang Persia), namun demikian ada juga etnik lain seperti Kurdi yang terdapat di sebelah barat Azerbaijan, Kurdistan, dan wilayah Kermanshah, yakni Suku Lur dan Suku Bakhtiari. Bahasa Persia dipakai oleh $80 \%$ populasi penduduk Iran. Selebihnya Lur dan Bakhtiari memakai Bahasa Luri dan Suku Kurdi memakai Bahasa Kurdis (Thohir, 2009: 193).

Berbeda dengan dunia Islam lainnya, Iran dengan madzhab resmi Syi'ah memiliki para anggota Imam yang terdiri dari para Mujtahid dan Mullah. Mereka itulah yang mempunyai otoritas untuk menafsir al Quran dan mengontrol penerapannya dalam kehidupan masyarakat sehari-hari. Dalam tradisi intelektual ilmiyah, Iran juga memiliki karakter tersendiri, di saat dunia Islam secara meluas dilanda kevakuman, mereka terus melakukan kerja-kerja kreatif dengan mengembangkan warisan-warisan intelektual muslim. Oleh karena itu, tidak aneh pada periode pertengahan, saat ijtihad mengalami stagnasi, ilmu pengetahuan dengan tradisi ilmiyah yang khas terutama filsafat Islam terus tumbuh di Bumi Persia dengan munculnya Theosofi Isyraqiyah oleh Suhrawardi al Maqtul, Shadhr al Din al Syirazi yang lebih dikenal Mulla Shadra hingga ke Haidar Amuli. Pada periode modern dapat disaksikan lahirnya tokoh-tokoh berkelas seperti Thabathaba'i, Mutohhari, dan Ali Syari'ati.

Pada dasawarsa pertama abad ke-21 ini, di saat banyak atau bahkan seluruh dunia/negara Islam tidak mampu berdiri tegak melawan keangkuhan Barat, Iran adalah satu-satunya yang tetap istiqamah pada Islamnya dan tidak gentar dengan gertakan, bahkan mampu membalas dengan sikap kritis sambil membawa bukti penguasaan ilmu dan teknologi. Iran memang tidak menutup diri dari sains dan teknologi, melainkan tetap pro aktif dengan pola relasi mengambil isi membuang kulitnya, menerima dan mengembangkan hal hal yang baik dari sains dan teknologi tetapi yang kotor-kotor dibuang. Dari sini dapat disaksikan bagaimana "keperkasaan" negara yang bahasa resminya banyak menghiasi warisan-warisan klasik khazanah pengetahuan Islam ini.

\section{Moralitas: Antara Islam dan Zoroastrian}

Sebenarnya tidak mudah untuk menentukan suatu perspektif ketika sesuatu tersebut belum disepakati batasan-batasannya. Demikian juga dalam tulisan ini, ketika penulis mencantumkan suatu kategori "Islam", misalnya. 
Dalam benak pembaca pasti muncul pertanyaan Islam yang mana, karena kenyataannya Islam telah terbagi dalam beberapa madzhab. Hal yang sama mestinya juga terjadi ketika suatu kelompok berkehendak menerapkan syari'ah Islam dalam tata sistem kenegaraan dan sosial di wilayah yang multikultural ini. Mengapa demikian? Hal itu, mungkin karena pada kenyataannya syari'at yang terimplementasi dalam hukum-hukum fiqih itu tidaklah tunggal tetapi, telah menjelma ke dalam berbagai madzhab. Madzhab-madzhab fiqih, seperti yang telah diketahui berbeda pendapat dalam satu kasus yang sama sekalipun.

Supaya tidak menimbulkan kesalahpahaman, penulis memberi batasan seperti yang dipahami penulis terhadap Islam. Seperti yang dipahami bukan berarti sembrono tanpa bertanggungjawab, akan tetapi sesuai yang penulis ketahui berdasarkan sumber tadwini (tertulis) maupun takwini (realitas alam). Pemahaman atas dasar yang diketahui sudah tentu subjektif sesuai pengalaman dan referensi yang dirujuk penulis. Kesubjektivan pandangan sebagai konsekuensi akal yang dianugerahkan Tuhan kepada manusia bukanlah suatu aib, melainkan wujud apresiasi dan pemanfaatan "nikmat Allah" berupa akal yang perlu dihargai. Dalam sebuah ungkapan, yang dipublikasikan oleh Sirri al Syaqathi, ada pula yang menganggapnya Hadits, disebutkan bahwa "تفكر سـاعة افضل من عبادة ألف "سنة " (bertafakkur dengan merenungkan segala apa yang terjadi sesaat lebih utama daripada beribadah seribu tahun). Betapa tingginya Allah menghargai buah pemikiran manusia, karena itu sungguh sebuah perbuatan yang tidak terpuji kalau hasil pemikiran itu dicela, apalagi disesat-sesatkan seolah hanya dia yang mencela itu yang benar.

Bertafakkur membutuhkan suasana tertentu yang kondusif, agar tidak bercampur antara buah pikiran yang jernih dengan buah godaan nafsu yang mengajak kepada kekotoran. Di antara contoh yang diberikan Nabi dalam tafakkur ini adalah berkhalwat (التحنّن) di Gua Hira, sedang para sufi mengajarkannya lewat uzlah (menjauh) dari hiruk-pikuk duniawi (al Qusyairi, tt: 102). Namun, hal ini jangan dipahami bahwa khalwat atau uzlah itu merupakan jalan penyelesaian masalah satu-satunya. Ia tidak lain hanyalah sarana untuk menemukan solusi. Setelah ditemukan solusi, tiada yang lebik baik selain mempraktikkannya dengan mencoba dan mencobanya lagi di dalam kehidupan nyata. Begitulah yang dicontohkan Nabi setelah keluar dari Gua Hira, demikian pula yang dilakukan para sufi, keluar dari Khaniqa (tempat belajar) setelah dianggap lulus oleh gurunya.

Islam adalah agama hanif yang menuntut kepasrahan penganutnya kepada tatanan (sistem) yang telah diciptakan Allah. Keislaman seseorang 
harus dinyatakan dengan tegas lewat kalimat "syahadah". Kepercayaan seseorang terhadap adanya Tuhan tanpa adanya pernyataan syahadah tidak bisa menjadikannya sah disebut sebagai seorang muslim. Begitu juga, kebaikan macam bagaimanapun, tanpanya (syahadah) akan tetap menjadikannya sebagai bukan Islam. Meskipun demikian, ketidakislaman itu bukan berarti menutup dia untuk disebut sebagai orang yang baik. Demikian pula hal itu tidak menghalanginya untuk bisa kembali ke sisi Tuhan dengan baik-baik. Itulah spirit yang mesti dimiliki seorang muslim hanif, sehingga ia bisa bergaul bebas dengan berbagai madzhab dan keyakinan keagamaan yang berbeda, tanpa mengurangi keimanaannya kepada Allah (al Zuhaili dalam al Munir pada surat al A'raf: 199).

Kebaikan yang tertulis pada judul artikel ini bermaksud menarasikan ajaran-ajaran etika dalam Islam dan Zoroaster, yaitu etika yang berhubungan dengan kehidupan sosial kemasyarakatan. Dengan mengetengahkan nilai kebaikan dari ajaran-ajaran moral kedua keyakinan itu sudah tentu juga tersangkut yang sebaliknya yaitu keburukan. Karena berbicara hal hal yang berkaitan dengan kehidupan sosial, sudah tentu ia merupakan ajaran mengenai tindakan nyata yang dapat diukur dan diamati, tanpa menelisik jauh ke dasar keimanan yang merupakan urusan hati. Pada dasarnya Islam adalah agama akhlak (moral), baik dan buruk keislaman seseorang diukur dengan moralitas yang dimunculkannya dalam tindakan keseharian (Imam Malik, al Muatho' dalam Maktabah Syamilah). Demikian juga ajaran orisinil agama Persia kuno, Zoroaster ini. Ia menuntun kepada moralitas yang baik secara sosial, yaitu berbuat baik terhadap sesama dan alam sekitar. Hanya saja, seperti juga Islam yang mengalami perkembangan dan perubahan, dari ajaran moral yang menata hati dan tingkah laku sosial itu kemudian terdistorsi oleh faktor sosial politik ke arah yang menekankan pada ibadah ritual saja, Zoroaster juga demikian (Antony, 2006: 11-3).

Perubahan-perubahan akibat perjalanan sejarah yang terjadi pada hampir semua ajaran keagamaan sudah merupakan kelumrahan akibat kepentingan kelompok yang terimplementasi dalam kekuatan sosial politik yang menjelma lewat kursi kekuasaan. Kesejatian moralitas Islami yang diajarkan dan dicontohkan Nabi, berkembang dengan nilai lebih dan kurang seiring pasang-surut moral pemimpinnya. Dalam perjalanan sejarah tersebut terbukti bahwa bukan hanya nilai agama dan budaya yang membentuk orang atau masyarakat, tapi juga bisa terjadi sebaliknya, orang atau masyarakat juga bisa membentuk nilai agama dan budaya. Keterlibatan nilai budaya dalam 
mewarnai ajaran agama itu, dalam sejarah perdaban Islam masuk melalui jalur kekuasaan politik (Antony, 2006: 422). Yang terjadi pada Zoroaster juga demikian (Anthony, 2006: 113).

Islam dan Zoroaster ada kemiripan. Dalam kitab suci Zoroaster (Zend Avesta) disebutkan bahwa penciptaan alam semesta seisinya ini terbagi dalam enam masa. Seperti agama-agama samawi yang lain, agama ini juga mempercayai adanya kehidupan setelah mati. Demikian juga mengenai manusia yang pertama, menurut ajaran Zoroaster manusia pertama adalah satu pasang, yaitu Mosyya dan Mosyyana (Anthony, 2006: 162). Ini adalah di antara kemiripan kandungan ajarannya yang berhubungan dengan sejarah penciptaan dan moral. Namun demikian, bukan sisi ini yang hendak disorot penulis, melainkan pada aspek moralitas, yaitu ajaran etika yang mengatur hubungan dengan sesama dan dengan lingkungan kehidupan sekitar.

Karena Zoroaster lahir dan berkembang di tengah kehidupan masyarakat agraris di masa Persia kuno, ajaran-ajarannya berhubungan dengan kehidupan pertanian. Orang saleh dalam pandangan Zoroaster adalah mereka yang dapat menanam pohon yang berguna, menyalurkan air ke tanah-tanah pertanian yang kering, menyingkirkan binatang-binatang yang berbahaya, dan melakukan segala pekerjaan demi keselamatan lingkungan (Smith, 2009: 4). Di atas telah disinggung sabda Nabi yang menghimbau umatnya agar bertafakkur untuk melakukan yang baik dan bermanfaat. Pada bagian lain Nabi memberi wejangan agar umatnya mampu memberi kontribusi nyata pada kemanusiaan, "خبر الناس انفعكم للناس". Sementara itu, Zaratustra, nabinya kaum Zoroastrian menegaskan bahwa orang yang menabur benih di lahan dengan cermat dan rajin, mendapatkan pahala yang lebih besar daripada yang dapat diperolehnya dengan hanya mengulang sepuluh ribu doa (Assagaf, 2009: 164).

Teologi Zaratustra dipahami secara samar oleh orang asing bahkan juga oleh penganutnya sendiri. Namun siapa pun akan terpaku oleh kesederhanaan falsafah pemujaan Persia. Dalam sejarah awal kelahiran ajarannya, Zarasturian menolak penggunaan kuil, altar dan patung-patung sebagai tempat dan wujud peribadatan. Sungguh tidak benar kalau diyakini bahwa para dewa berasal, atau mempunyai tempat tinggal di alam manusiawi. Puncak dari kebaikan sebagai persembahan manusia ada pada kesediaannya untuk berkorban, yaitu berkorban dengan hati yang tulus untuk kemaslahatan. Kaum Zarasturian bukanlah penyembah alam seperti bumi, api, angin, air, matahari serta bulan. Akan tetapi, objek-objek itu, terutama matahari, cahaya dan api yang mereka sebut Mithra adalah objek yang perlu dihormati karena dianggap sebagai 
simbol yang paling murni dan mulia serta paling kuat dari kekuasaan Tuhan (Assagaf, 2009: 151).

Pada setiap agama bisa ditemukan jejak tauhid yang mengandung ajaran monotheism, namun seringkali hal itu dikaburkan oleh perjalanan sejarah dan intervensi politik oleh kekuasaan yang mencengkeram saat tertentu. Setiap agama pasti menuntut ketaatan manusia dengan perintah mempraktikkan pengabdian kepada Tuhan. Perintah itu harus dihormati dengan memasukkan kewajiban moral yang dapat diibaratkan sebagai perintah hati sendiri. Itulah basis moral ajaran Ahura Mazda yang menganugerahkan kebebasan kepada manusia dengan memberikan kekuasaan untuk memilih perbuatannya sendiri, yaitu diberi kehendak bebas sehingga dapat memilih antara yang baik dan yang buruk.

Dalam Zoraster, manusia memiliki kewajiban moral untuk berbuat adil, berbelas kasih terhadap sesama dengan sikap kedermawanan. Hanya dengan mewujudkan sikap-sikap demikian orang bisa melepaskan diri dari cengkraman Ahriman, yaitu roh jahat yang selalu mengajak kepada keburukan. Apabila kewajiban moral itu telah terpenuhi orang akan bisa hidup dalam kekekalan dan penuh berkat, dimana derajat kebahagiaan sebanding dengan kebajikan dan kesalehan yang dijalankan (Assagaf, 2009: 152).

Dalam penghormatan terhadap ahli agama, pendeta atau magi, yaitu ulama, guru atau mursyid dalam termonologi sufisme, Zoroaster menuntut hal yang sama seperti murid kepada guru. Edward Gibbon, dalam The Declin and Fall of the Roman Empire, seperti dikutip Muhammad Hasyim Assagaf mengatakan:

"Walaupun pekerjaan kamu yang baik melebihi jumlah daun pohonpohonan, tetesan hujan, bintang di langit, atau pasir di pantai, semua itu tidak akan menguntungkan kamu, apabila kamu tidak diterima oleh pendeta. Untuk mendapatkan penerimaan bimbingan ke arah keselamatan, engkau harus dengan jujur membayar pajak keagamaan atas segala yang kau miliki, dari harta, dari tanah, dan dari uangmu. Apabila pendeta puas, jiwamu akan luput dari siksaan neraka, engkau akan mendapatkan pujian di dunia dan akan mendapatkan kebahagiaan di alam yang akan datang" (Assagaf, 2009: 154).

Para Magi di Persia adalah pemegang otoritas di bidang pendidikan. Ucapan mereka cermat, berkesan dan sangat membekas di kalangan rakyat. Para Magi itu adalah para jenius dan dikenal sebagai pemikir spekulatif, dengan tradisi turun-temurun suka memelihara dan menyelidiki rahasia-rahasia falsafah Timur. Dengan keunggulan itu, ada komentar dari sejarawan Yunani, Plinius 
(23-79 M), mengatakan bahwa para Magi menguasai masyarakatnya dengan tiga ikatan: agama, kejiwaan, dan astronomi. Situasi Persia yang seperti itu terjadi di masa pemerintahan Ardasyir, dimana nasihat-nasihat ordo kependetaan banyak mengarahkan kebijakan-kebijakan raja dalam menetapkan aturanaturan (Assagaf, 2009: 155).

Zaratustra sebagai pembawa dan penyebar teologi Zoroastrian awal hidup di tengah masyarakat agraris. Konteks sosio-budaya yang seperti itu menginspirasinya untuk memberikan ajaran-ajaran moral yang berkaitan dengan alam pertanian. Karena itu, kebaikan dan kesalehan dari sisi pandang praktis Zaratustra terletak pada upaya pembudidayaan tanah, upaya menghasilkan padi dan sayur-sayuran, menyiangi gulma yang mengganggu tanaman, mengairi lahan pertanian yang kering, mengurusi hewan yang bermanfaat, seperti sapi yang amat berguna dalam pengolahan tanah. Dari beberapa ajaran yang dikandung dalam doktrin Zoroastrian ini dapat disimpulkan bahwa orang baik akan selalu setia pada kebenaran dan benci terhadap kebatilan. Sebaliknya, orang yang jahat adalah orang yang membiasakan diri dengan hal hal yang buruk, tidak pernah menaruh perhatian atas pekerjaan. Sifat demikian ini yang disenangi oleh Ahriman, yaitu dewa kegelapan yang selalu memusuhi Ahura Mazda (Assagaf, 2009: 165).

Dalam al Quran, gambaran sifat-sifat buruk yang menjadi lawan kebaikan itu ada pada ciri-ciri orang munafik. Orang-orang munafik, menurut al Quran, yang laki-laki maupun yang perempuan, semuanya mereka itu adalah sama, mereka menyuruh kepada perbuatan-perbuatan yang munkar dan melarang yang ma'ruf "يأمرون بالمنكر وينهون عن المعروف". Terhadap harta yang dimiliki, mereka "menggenggamkan tangannya", yaitu berlaku kikir. Mereka enggan membantu sesama, mereka telah lupa kepada Allah. Oleh karena itu Allah pun melupakan mereka. Orang-orang munafik itu tidak lain adalah orangorang yang fasik, yaitu orang yang telah tahu aturan etika tapi tidak mau mengamalkannya dalam kehidupan nyata (QS at Taubah: 67).

Pada Islam dikenal Hadits Nabi yang menganjurkan umatnya untuk mandiri dengan bekerja keras untuk menopang hidupnya. Dikatakan pula bahwa seorang muslim/beriman yang kuat lebih dicintai Allah daripada yang lemah. Nabi menganjurkan umatnya untuk bekerja, bukan meminta-minta (Qardhawi, 1985: 124). Islam memang menghargai usaha dan kekuatan. Hal yang sama juga ada pada Zoroaster. Sayyed Taghi Nasr, seperti yang dikutip Assagaf mengatakan bahwa meminta-minta dalam pandangan etika-religius Zoroaster dianggap sebagai kejahatan besar. Barang siapa menabur gandum, 
ia menabur kebaikan, yang berarti ia memajukan agama. Bukan hanya itu, ajaran tentang kebersihan juga mendapatkan porsi yang cukup besar. Dalam Avesta ada kalimat yang menegaskan bahwa kebersihan adalah kebaikan kedua yang perlu diperhatikan setelah kelahiran. Kesucian adalah hukum Mazda. Kesucian itu berarti suci dalam pikiran, perkataan dan perbuatan (Assagaf, 2009: 166).

Sebagai keyakinan yang telah organized, sehingga membentuk sistem yang bisa disebut agama, penganut Zoroaster, atau ada pula yang mengidentikkan dengan Majusi oleh kaum muslimin yang masuk pertama kali ke Persia dikatakan sebagai ahlu kitab, sebagaimana Yahudi dan Kristen. Murtadha Mutthahari, sebagaimana dikutip Assagaf berpendapat bahwa Zoroaster dapat digolongkan sebagai agama tauhid, yakni penganut monoteisme. Aneka ragam syirik yang hadir mengiringi perkembangannya, seperti dualisme (Ahura Mazda dan Ahriman), pemujaan api dan lain sebagainya merupakan bid'ah-bid'ah yang datang dari luar merasuki kemurnian ajarannya. Dengan tidak ditemukannya secara pasti unsur non-monoteis ajaran Zoroaster asli, tidak ada halangan untuk memandangnya sebagai agama monoteisme seperti yang lain.

\section{Simpulan}

Dalam sejarah intelektual Islam di masa keemasannya (عصر الازدهار), tidak ada perbedaan antara filusuf (failusuf) dan alim atau ulama dalam tradisi Indonesia. Para filusuf pendahulu yang dikenal dikalangan kaum muslimin sebenarnya adalah seorang intelektual yang ahli di bidang ilmu agama yang secara otomatis juga ahli di bidang ilmu bahasa. Filusuf atau alim adalah pemikir di bidang keagamaan dan ilmu-ilmu lain sekaligus. Sebagai pemikir mereka berkewajiban memikirkan apa saja yang terjadi dan dilihat, kemudian menuliskan hasil refleksinya atas peristiwa tersebut agar menjadi tuntunan untuk orang atau generasi berikutnya. Namun demikian, pada penggal kesejarahan tertentu, ada yang membedakan antar filusuf dengan alim. Filusuf dipahami sebagai orang yang bebas tanpa kendali dalam berpikir, sampai rambu-rambu Kitab Suci pun dilanggar, sedangkan alim kebalikannya.

Untuk menghindari debat yang tak urgen mengenai kebahasaan itu, barangkali lebih tepat di sini, dalam konteks pembahasan etika, mereka disebut saja sebagai muadzib (المؤدبّ), karena kita memang hanya berbicara masalah moral praktis sebagai acuan dalam bertindak. Ajaran moral ini terdapat dalam Hadits "atau dalam kitab al Muwattha' karya Imam Malik yang ئأمر) mengatakan bahwa Nabi memerintahkan kepada moralitas yang mulia 
(بمكارم الأخلاق. Memang telah banyak para ahli adab menulis risalah yang sarat dengan ajaran moral. Telah jelas pula bahwa pedoman pokok ajaran Islam, al quran dan al Hadits pada dasarnya adalah pegangan tentang etika Islam.

Kepustakaan adab Islam, menurut George A. Makdisi dalam The Rise of Humanism in Classical Islam and the Christian West bermula dengan kemunculan Ibnu al Muqaffa yang mengenalkan pemikiran India ke dunia Islam melalui terjemahan dongeng-dongeng Bidpa dalam bukunya Kalilah wa Dimnah, dan pemikiran moral Persia melalui bukunya al Adab al Kabir dan al Adab al Shagir ke dalam Bahasa Arab. Karena itu, pengenalan pemikiran India dan Persia mendahului pengenalan pemikiran Yunani dalam bidang etika dan Filsafat Moral (Makdisi, 2005: 536). Tradisi yang berasal dari kebudayaan luar itu kemudian segera disesuaikan dengan standard moralitas Islam, dan diadopsi oleh Ibnu Qutaybah (w. 276 H/890 M) dalam karyanya Uyun al Akbar. Kemudian dikembangkan lebih lanjut oleh para filosof muslim yang kesohor seperti Ibnu Miskawaih, al Ghazali, Ibnu Rusydi dan lain sebagainya.

Kebaikan adalah kebenaran itu sendiri dalam wujudnya yang mandiri. Ia bisu dan sering dalam kesunyian, seperti "surga" yang kata Nabi selalu diliputi hal hal yang kurang disuka. Dalam Islam, kebaikan itu ada pada wahyu yang tertulis dan tidak tertulis. Pada yang tertulis, terdapat anjuran untuk melihat dan mengambil nilai baik dari mana saja, sedang pada yang tidak tertulis manusia dianjurkan untuk terus belajar dari realitas yang teramati agar ajakan kepada kebaikan itu mendapat respons. Pada dasarnya, kehidupan ini mewujud karena adanya yang ada dan tiada, adanya terang dan gelap, adanya yang melihat dan yang buta, adanya yang sempurna dan kurang, adanya yang benar dan yang salah, dan begitu seterusnya, dua entitas yang tampak berlawanan tapi sebenarnya bersandingan untuk menguji batas kecerdasan akal dan hati manusia dalam memilih.

\section{Daftar Pustaka}

Alhadar, Smith. Peny. 2009. Iran Tanah Peradaban. Jakarta: Kedutaan Besar Republik Islam Iran.

Al Qardhawi, Yusuf. 1985. Al Halal wa al Haram Fi al Islam. Dar al Ma'rifah.

Assagaf, Muhammad Hasyim. 2009. Lintasan Sejarah Iran: Dari Dinasti Achaemania Sampai Revolusi Islam. Jakarta: The Cultural Section of Embassy of The Islamic Republic of Iran. 
Black, Anthony. 2006. Pemikiran Politik Islam. Terjemahan oleh Abdullah Alu dan Mariana Ariestyawati. Jakarta: Serambi Ilmu Semesta.

Lapidus, Ira M. 2000. Sejarah Sosial Umat Islam. Terjemahan oleh Gufron A. Mas'adi. Jakarta: Raja Grafindo Persada.

Maksidi, George A. 2005. Cita Humanisme Islam. Terjemahan oleh A.Syamsu Rizal dan Nur Hidayah. Jakarta: Serambi Ilmu Semesta.

Thorir, Ajid. 2009. Studi Islam Kawasan. Jakarta: Rajawali Press.

Tim Redaksi Ensiklopedi Islam. 1994. Ensiklopedi Islam. Jakarta: PT. Ichtiar Baru Van Hoeve.

Yazdi, M.T. Misbah. 2006. Meniru Tuhan. Terjemahan oleh Ammar Fauzi Heriyadi. Jakarta: Al Huda. 